\title{
Chlorophyll-a Estimation Around the Antarctica Peninsula Using Satellite Algorithms: Hints from Field Water Leaving Reflectance
}

\author{
Chen Zeng ${ }^{1,2, *}$, Huiping $\mathrm{Xu}^{1,3}$ and Andrew M. Fischer ${ }^{4}$ \\ 1 School of Ocean and Earth Science, Tongji University, Shanghai 200092, China; xuhp@sidsse.ac.cn \\ 2 Department of Earth, Ocean and Atmospheric Sciences, University of British Columbia, \\ Vancouver, BC V6T 1Z4, Canada \\ 3 Institute of Deep-Sea Science and Engineering, Chinese Academy of Sciences, Sanya 572000, China \\ 4 Institute for Marine and Antarctic Studies, University of Tasmania, Launceston 7250, Australia; \\ andy.fischer@utas.edu.au \\ * Correspondence: 07zengchen@tongji.edu.cn; Tel.: +1-778-885-0301
}

Academic Editors: Assefa M. Melesse, Essayas Kaba Ayana and Gabriel Senay

Received: 8 August 2016; Accepted: 21 November 2016; Published: 7 December 2016

\begin{abstract}
Ocean color remote sensing significantly contributes to our understanding of phytoplankton distribution and abundance and primary productivity in the Southern Ocean (SO). However, the current SO in situ optical database is still insufficient and unevenly distributed. This limits the ability to produce robust and accurate measurements of satellite-based chlorophyll. Based on data collected on cruises around the Antarctica Peninsula (AP) on January 2014 and 2016, this research intends to enhance our knowledge of $\mathrm{SO}$ water and atmospheric optical characteristics and address satellite algorithm deficiency of ocean color products. We collected high resolution in situ water leaving reflectance ( $\pm 1 \mathrm{~nm}$ band resolution), simultaneous in situ chlorophyll-a concentrations and satellite (MODIS and VIIRS) water leaving reflectance. Field samples show that clouds have a great impact on the visible green bands and are difficult to detect because NASA protocols apply the NIR band as a cloud contamination threshold. When compared to global case I water, water around the AP has lower water leaving reflectance and a narrower blue-green band ratio, which explains chlorophyll-a underestimation in high chlorophyll-a regions and overestimation in low chlorophyll-a regions. VIIRS shows higher spatial coverage and detection accuracy than MODIS. After coefficient improvement, VIIRS is able to predict chlorophyll a with 53\% accuracy.
\end{abstract}

Keywords: water leaving reflectance; skylight downwelling radiance; chlorophyll-a estimation; MODIS; VIIRS

\section{Introduction}

The Southern Ocean (SO) contains relatively high seasonal levels of phytoplankton biomass in its coastal waters due to the complex processes of ice melt and intense seasonal light availability. Seasonal blooms in this region play a significant role in driving global biogeochemistry cycling [1,2]. Satellite imagery can provide high spatial and temporal coverage of the SO in the southern spring and summer (from October to March), and is useful for understanding the patterns and variability of phytoplankton biomass across broader temporal and spatial scales. This is an advantage over in situ environmental detection $[3,4]$, where severe weather can make routine and comprehensive sampling difficult.

However, imperfect atmospheric correction of satellite images over the SO region produces uncertainty in chlorophyll-a estimation [5-7]. For example, the OC2v2 algorithm, when applied to CZSC and SeaWiFS imagery, underestimated chlorophyll-a $\left(0.7-43 \mathrm{mg} / \mathrm{m}^{3}\right)$ concentrations by $60 \%$ in the west marginal sea of the Antarctic Peninsula [8]. A potential reason for this is that the SO 
water-leaving reflectance (Rrs) is high in the blue band $(443 \mathrm{~nm})$ and low in green band $(555 \mathrm{~nm})$, when compared with the global open ocean [9]. An underestimation of $87 \%$ was also found in the chlorophyll concentration range of $0-1.0 \mathrm{mg} / \mathrm{m}^{3}$ and by $30 \%$ in concentration values of $>5 \mathrm{mg} / \mathrm{m}^{3}$ in the South Georgia area $\left(54.5^{\circ} \mathrm{S}, 37^{\circ} \mathrm{W}\right)$ [10]. A strong relationship was reported between inversion and in situ chlorophyll-a estimates, however, underestimation still existed for chlorophyll concentrations between 0.1 and $1.5 \mathrm{mg} / \mathrm{m}^{3}$ in the Ross Sea [4]. The OC3 algorithm coefficients were improved with in situ samples and provided better agreement $\left(r^{2}=0.64\right)$ near the Antarctica Peninsula [11]. Since all inversions above have their own scope and regional limitation, SO chlorophyll-a inversion accuracy deserves improvement to enhance chla estimation.

The aim of this study is to assess the accuracy of satellite-based chlorophyll-a estimation within coastal Antarctic waters. Through the collection of hyper-spectral downwelling irradiance and water leaving reflectance (Rrs) around the West Antarctica Peninsula (WAP), an area which lacks a sufficient in situ validation datasets for satellite remote sensing, we evaluate the chlorophyll-a algorithm estimations from three aspects: first, the downwelling irradiance total signal was collected just above the sea surface and was used to derive atmospheric spectral information such as particle scattering and gas and aerosol absorption; second, the hyper-spectral $\operatorname{Rrs}( \pm 1 \mathrm{~nm})$ were used to determine detailed bio-optical characteristics of WAP waters; finally, our data were collected after launching of VIIRS. For this new sensor, reflectance validation samples are seldom available from SeaBASS [12]. This manuscript makes a comparison between MODIS and VIIRS performance using current OC satellite chlorophyll-a algorithms and improves regional chlorophyll-a estimation coefficients of OC algorithms.

\section{Materials and Methods}

\subsection{Above Water Measurement and Processing}

Our research measured nine water leaving reflectance samples between 10 and 19 February 2014 (Figure 1b) and 30 water leaving reflectance (Rrs) samples around AP between 6 and 27 January 2016 (Figure 1c). An ASD Fieldspec HandHeld 2 was used to obtain water leaving reflectance with high band resolution of $\pm 1 \mathrm{~nm}$ and a spectral range from 325 to $1075 \mathrm{~nm}$, containing visible and infrared bands. The device had conducted band peak shifting calibration, standard plaque reflectance calibration, and sensor radiance calibration before and after cruises.

Hyper-spectral downwelling irradiance and water leaving reflectance were based on above-water measurements using the methods of Mueller et al. [13]. Compared with under water measurements, above-water measurement provide many advantages. First, they are of higher spectral resolution ( $\pm 1 \mathrm{~nm}$ band resolution) as underwater devices have limited spectral bands (profiling reflectance radiometer has six upwelling and downwelling irradiance in 412, 443, 490, 555, and $656 \mathrm{~nm}$ ). Underwater measurements also need to be extrapolated to surface values, a process which usually introduces uncertainty [14]. Second, above water leaving reflectance can be directly compared to satellite derived normalized water-leaving $(\mathrm{nLw})$ radiance. Third, underwater measurements are also subject to air water interface transformation [15], which varies when light incident angle changes.

Simultaneous meteorological parameters such as sea ice location, sky clarity index, and wind speed were also recorded. Overcast weather appeared during almost the whole sampling period. The homogeneous light condition from overcast weather produced a uniform skylight radiance condition more conducive for Rrs measurements than cloudy conditions or intense glare [14]. Under cloudy conditions and intense glare, water receives heterogeneous and patchy irradiance and reflects a variety of light intensity in different scattering angles. This creates difficulties for atmospheric correction and can lead to uncertainties in Rrs detection.

According to the ocean color protocol [13], we sampled above-water Rrs within the recommended zenith $(\theta)$ and azimuth $(\Phi)$ angles at $40^{\circ}$ and $135^{\circ}$. A fishing rod of $3 \mathrm{~m}$ length was held to avoid shipboard interference. We collected 15 samples of water, skylight and standard plague measurements at each sampling location. Every sample had 2 duplicates. For each sample, we chose a minimum of 
10 signals and averaged them to get water, skylight and standard plaque signal to decrease the signal noise for each sample.

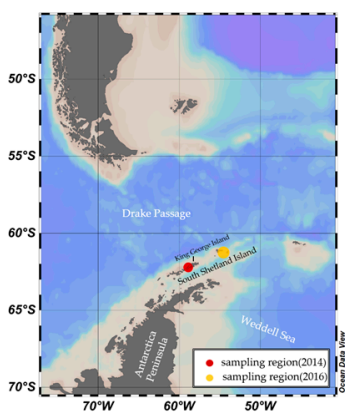

(a)

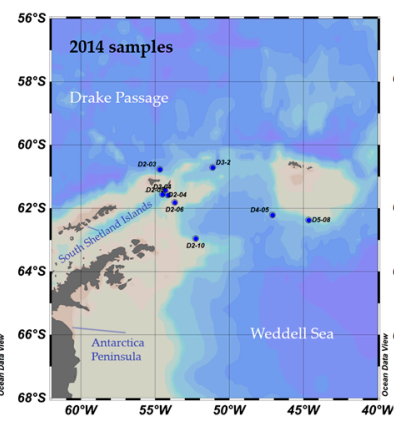

(b)

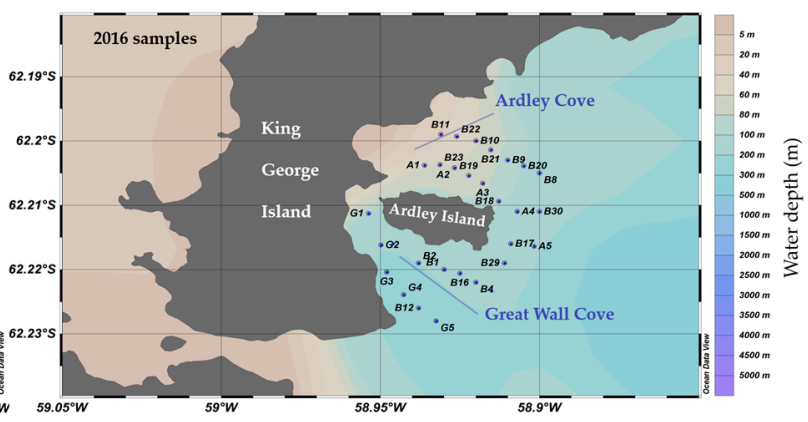

(c)

Figure 1. (a) Map of sample distribution in SO around Antarctic Peninsula with topography from ETOPO1 [16]; (b) Map of detail sample distribution during 10 February to 19 February 2014; (c) Map of detail sample distribution during 6 January to 27 January 2016.

Because the air-water interface ratio (r) changes with wind speed, we followed the methods of [17] to computer $r$ (see Equation (1)). To improve the atmospheric correction, we used $936 \mathrm{~nm}$ as the infrared black pixel. The $r$ value in this manuscript from AP data is $4.4 \pm 1.1$ (\%). Then, Equation (2) [18] was applied to obtain water-leaving reflectance from respective water, skylight and standard plaque signal. Finally, all bands were offset by the value at $936 \mathrm{~nm}$ :

$$
\begin{gathered}
r=\frac{S_{\text {water }\left(\lambda_{936}\right)}-0.015 \times S_{\text {sky }}\left(\lambda_{936}\right)}{S_{\text {sky }}\left(\lambda_{936}\right)} \\
R_{r s}=\frac{\left[S_{\text {water }}-r S_{\text {sky }}\right] \times \rho_{p}}{\pi \times S_{p}}
\end{gathered}
$$

where, $\mathrm{r}$ is air-water interface reflectance rate (\%) [13], Rrs is water-leaving reflectance $\left(\mathrm{sr}^{-1}\right), S_{\text {water }}$, $S_{s k y}, S_{p}$ is the digital signal value measured for water, skylight and standard plaque radiance, $\rho_{p}$ is the standard plaque bi-directional reflectance ( $99 \%$ for this study) and $\lambda_{936}$ is band wavelength $936 \mathrm{~nm}$. High bi-directional reflectance (99\%) provided a high signal-to-noise ratio (SNR) for the downwelling irradiance signal [14]. This process eliminates atmosphere interference and provides a normalized Rrs.

\subsection{In Situ Chlorophyll-a Measurements}

Samples for chlorophyll-a concentration were filtered onto $47 \mathrm{~mm}$ glass fiber filters (GF/F) using low vacuum pressure $(<10 \mathrm{~mm} \mathrm{Hg})$, wrapped with aluminum foil and immediately stored at $-80{ }^{\circ} \mathrm{C}$ until analysis within two months. Each sample was collected in duplicate with $500 \mathrm{~mL}$ water for each. Then, chlorophyll-a was extracted by $90 \%$ acetone overnight and centrifuged for $10 \mathrm{~min}$. Finally, its supernatant was analyzed in a 10AU ${ }^{\mathrm{TM}}$ Field and Laboratory Fluorometer for total chlorophyll-a. After adding $10 \% \mathrm{HCl}$ and settling for $1 \mathrm{~min}$, the pheophytin concentration was also collected. Chlorophyll-a concentration was calculated by the chlorophyll-a standard curve. The chlorophyll-a standard curve was regressed with the chlorophyll-a standard product from Sigma Aldrich across various concentration gradients. All analyses were conducted under dim light. 


\subsection{Spectrum Sensitivity Analysis}

To determine the best band for satellite chlorophyll-a estimation, we applied Gitelson et al.'s [19] algorithm on spectrum sensitivity. For band-ratio algorithm:

$$
\text { chlorophyll } \alpha \sim \frac{\text { blue band }}{\text { green band }}
$$

Using $488 \mathrm{~nm}$ as the blue band and $400 \mathrm{~nm}$ as the green band we calculated the ratio of $488 \mathrm{~nm} / 400 \mathrm{~nm}$. We then applied least-squares method to approximate the linear-regression coefficients between the ratio values from all of the field Rrs samples and in situ chlorophyll-a $(n=39)$, and estimated the residual error. Then we moved the green band choice one by one, till we reached the $700 \mathrm{~nm}$ band wavelength. When plotting all of the estimated residual error for different green band selections, we will get the optimal band for green band chlorophyll-a estimation. Next we confirmed green band at the optimal green band choice and applied above method to traverse all of 400-700 nm to find the optimal blue band.

\subsection{Satellite and In Situ Derived Data Matching}

For matching pairs between in situ and satellite data, we collected all images from visible bands in MODIS AQUA/TERRA (443, 469, 488, 531, 555, 645, 667, $678 \mathrm{~nm})$ and VIIRS (410, 443, 486, 551, $671 \mathrm{~nm}$ ) during the cruises. These daily L3 water leaving reflectance products have a spatial resolution of $4.25 \mathrm{~km}$ and have been georeferenced and atmospherically corrected. These products can be directly compared with our in situ reflectance water measurements. Due to overcast weather during almost all of the sampling period, we chose the following thresholds for matching in situ and satellite pairs, (1) interval time between in situ and satellite derived samples was no more than $72 \mathrm{~h}[7,20]$; and (2) satellite $3 \times 3$ grid pixel window were averaged at the center of in situ sample location to lower data noise and cloud interference $[21,22]$. This temporal threshold won't decrease the accuracy, because Johnson et al. [20] found SO multi-day composite products ( 8 day) still provided good agreement with in situ samples.

\subsection{MODTRAN-Based Atmospheric Downwelling Radiance Simulation}

The above-water methodology [13] and ocean color protocol applies the same rule to subtract atmospheric signal from total water-leaving radiance. While above-water methodology measures skylight downwelling radiance directly and then subtracts it from total water-leaving radiance, satellite correction applies pre-calculated atmospheric radiation transfer models to simulate atmospheric signals, where its aerosol absorption is estimated by sensors' near infrared bands. Thus we compared field skylight downwelling radiance and MODTRAN simulated total radiance to study the deficiencies of the current atmospheric simulation around AP.

MODTRAN (version 5) was used here and major options were: MODTRAN scaled discrete ordinate radiance transfer, $\mathrm{H}_{2} \mathrm{O}$ component at $0.4,1 \mathrm{~g} / \mathrm{cm}^{3}$, marine aerosol (default visibility $23 \mathrm{~km}$ ), nimbostratus cloud layer, wind speed $7.74 \mathrm{~m} / \mathrm{s}$. Path type: $40^{\circ}$ sun zenith angle and $120^{\circ}$ sun azimuth angle according to field measurements. Normalization process (percentage $(\%)=\left(S_{\text {skylight }}(\lambda)\right) /\left(\max \left(S_{\text {skylight }}\right)\right) \times 100 \%$, where $\lambda$ is band number $)$ was then performed to eliminate environmental effect on individual samples.

\section{Results}

\subsection{Skylight Downwelling Radiance}

Total downwelling radiance is the incident contribution reaching sea surface, which is a summation of extraterrestrial downwelling irradiance, Rayleigh scattering, gas and aerosol absorption $[23,24]$. The rule of atmospheric correction is to remove all those contributions from 
atmosphere, leaving only water-leaving radiance for the derivation of an ocean color product. Atmospheric correction is important for water-leaving reflectance because the atmosphere comprises over $90 \%$ of the total water leaving signal [25].

No obvious gaps appear in the mid-latitude summer atmosphere and high-latitude winter atmosphere simulations, both showing a similar tendency to decrease from around $465 \mathrm{~nm}$ (Figure 2). However, the high-latitude summer model values are about 3.99\% lower than mid-latitude summer model during 600-900 $\mathrm{nm}$ band interval. Those two MODTRAN simulation are the models with greatest gap between all six atmospheric models (Tropical Atmosphere, Mid-Latitude Summer, Mid-Latitude Winter, Sub-Arctic Summer, Sub-Arctic Winter, 1976 US Standard Atmosphere).

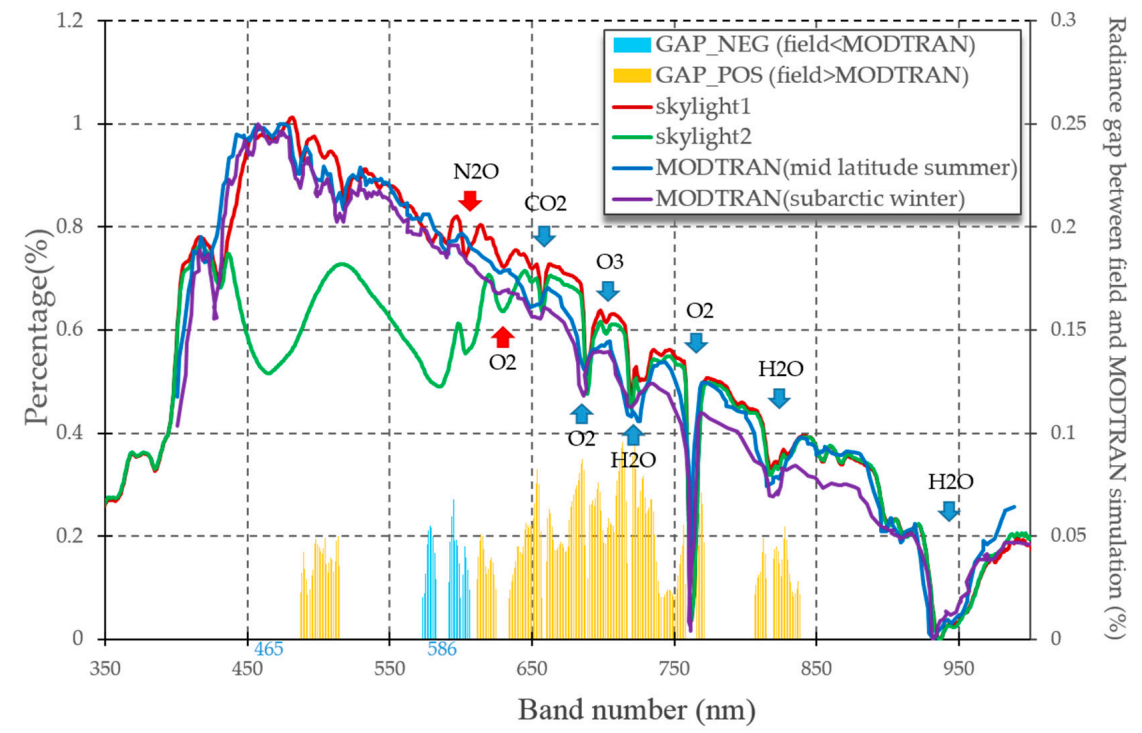

Figure 2. Skylight downwelling radiance distribution from AP and MODTRAN simulation. The histogram is the skylight1 subtracting from the MODTRAN Mid-Latitude summer simulation.

Skylight 1 \& 2 are common samples for skylight spectra collected in AP. Skylight 1 shows great agreement with MODTRAN simulations, especially with the Mid-Latitude Summer model. Mid-Latitude summer model appears to be the optimal model for AP total downwelling radiance simulation. Their near infrared bands are quite similar, and identical absorption peaks are located at 690, 720, 760, 810 and $930 \mathrm{~nm}$ due to the atmospheric gas window [26]. Most of their gaps are less than $5 \%$. Improvement is still needed for $\mathrm{N}_{2} \mathrm{O}(604 \mathrm{~nm})$ and $\mathrm{O}_{2}(630 \mathrm{~nm})$ gas absorption windows to better simulate AP total radiance (red arrows). Skylight 2 appears quite different from the above three (Skylight 1 and 2 MODTRAN simulations). According to field tests, those two obvious absorption peaks during 430-650 nm band intervals were caused by cumulus clouds.

\subsection{Water Leaving Reflectance Characteristics}

All of our water leaving reflectance (Rrs) samples have identical distributions and their duplicates have a standard error of less than $2.2 \pm 1.8 \times 10^{-4} \mathrm{sr}^{-1}$. Examples are shown in Figure 3, at chlorophyll-a concentrations $<1 \mathrm{mg} / \mathrm{m}^{3}$. The Rrs samples we collected and show the same tendency and range as those by Dierssen and Smith's [8] samples collected from AP as well. The value of $0.48 \mathrm{mg} / \mathrm{m}^{3}$ chlorophyll-a sample matches Dierssen and Smith $0.5 \mathrm{mg} / \mathrm{m}^{3}$ chlorophyll-a sample of Rrs. All AP Rrs (chlorophyll-a $<1 \mathrm{mg} / \mathrm{m}^{3}$ ) in Figure 3 range from 0.0009 to $0.0082 \mathrm{sr}^{-1}$. A turning point appears at about $490 \mathrm{~nm}$. Their blue band values are high and steady between $400 \mathrm{and} 490 \mathrm{~nm}$. Water-leaving reflectance between 495-570 $\mathrm{nm}$ and 570-590 nm decrease steeply, followed by smooth and low water-leaving reflectance in $>600 \mathrm{~nm}$. 


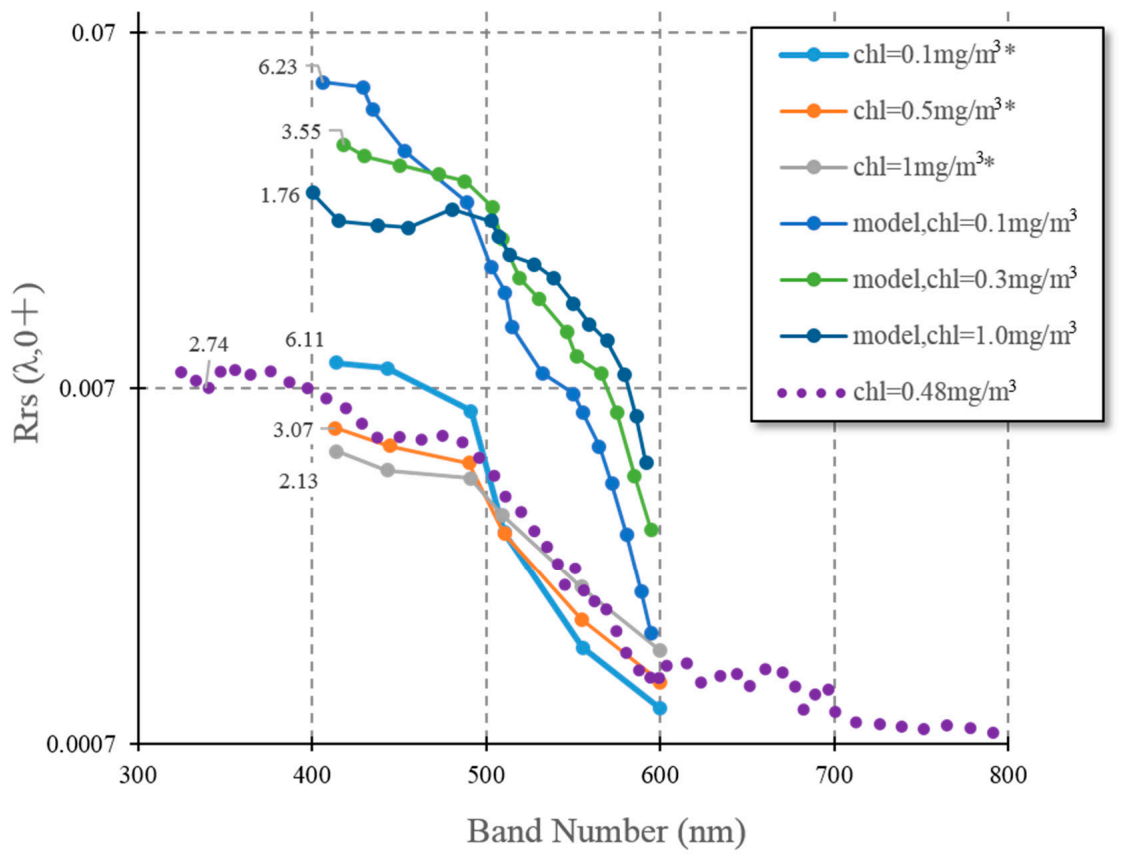

Figure 3. Water leaving reflectance spectrums around AP. The dot line is from our measurements, the lower three dash dot lines are in situ water spectrums in AP from Dierssen and Smith [8], and the other three dash dot lines with asterisk in legend are global water spectrum models from Morel and Maritorena [15]. The value ahead of each line is blue-green band ratio, $\max (\operatorname{Rrs}(\mathrm{blue}, 443)$, $\operatorname{Rrs}($ blue,488))/Rrs(green,555).

Global case I Rrs models from Morel and Maritorena [15] show greater values than those found in the $\mathrm{AP}$, with ranges between 0.0014 and $0.05 \mathrm{sr}^{-1}$ (chlorophyll-a $<1 \mathrm{mg} / \mathrm{m}^{3}$ water). These differences highlight the peculiar optical features from AP waters. However, they share same turning point at about 490-500 nm followed by a rapid decrease in values for lower chlorophyll-a after that point. Before this turning point, reflectance with lower chlorophyll-a have higher values. It is noticed that AP water spectrums decline slowly and is smoother than global open ocean water due to its low Rrs value.

The blue-green band ratios computed by $\max (\operatorname{Rrs}($ blue,443), $\operatorname{Rrs}($ blue,488))/Rrs(green,555) decrease with rising chlorophyll-a value in both global case I and AP waters. Global ocean waters have greater band ratio gaps between 0.1 and $1.0 \mathrm{mg} / \mathrm{m}^{3}$ chlorophyll-a range, meaning that band ratio variances become smaller in AP than in global ocean water. It is noted that the band ratio for our sample is 2.74 at $0.48 \mathrm{mg} / \mathrm{m}^{3}$ chlorophyll-a, which differs slightly from Dierssen and Smith's [8] band ratio 3.07 at $0.5 \mathrm{mg} / \mathrm{m}^{3}$ chlorophyll. The OC 3 algorithm shows that this gap equals $\sim 6.3 \%$ per chlorophyll-a unit, which is just a small uncertainty in chlorophyll-a evaluation. This error is probably caused by different methods and processing procedures.

\subsection{In Situ and Satellite Water Leaving Reflectance}

We matched in situ and satellite data successfully obtaining 24 matching pairs for MODIS and 30 for VIIRS. The reason we choose $3 \times 3$ pixels and $72 \mathrm{~h}$ window are listed as follows. Water leaving reflectance (Rrs) signals are scattered light from the upper ocean layer, which means Rrs only contains information from the oceanic euphotic layer after ideal atmosphere information is removed. Rossby waves have higher temporal and spatial scales than window of $12 \mathrm{~km} \times 12 \mathrm{~km}$ and $72 \mathrm{~h}$, so this window selection won't be impacted by Rossby wave.

Besides, water around AP, controlled by phytoplankton, shows seasonal patterns due to light, nutrient and sea ice distribution [11,27]. Therefore, the ocean current field and phytoplankton concentration has greater temporal and spatial scale than this window and will remain uniform 
under this limitation. The data in our research also shows that the spatial standard error in the window is less than $\sim 5.64 \%$ (calculated from the data in Table 1), and the temporal standard error of $72 \mathrm{~h}$ are less than $\sim 8.26 \%$ (calculated from all remote sensing data during October 2013 and March 2014 at the same location as our samples), which supports our selection of this spatial and temporal window. More VIIRS matching pairs $(n=30)$ were extracted than MODIS, illustrating thehigher spatial coverage and more effective detection performance of VIIRS. Daily coverage rates showed that VIIRS measured more SO surface ocean area than MODIS by about $1.1 \%$ due to its lower SNR and greater spectral range than MODIS [28]. High SNR makes the satellite signal susceptible to information loss and more vulnerable to atmosphere gases and aerosols [28].

Table 1. Matching pairs statistics for MODIS and VIIRS.

\begin{tabular}{|c|c|c|c|c|c|c|c|}
\hline Satellite & $\begin{array}{c}\text { Matching } \\
\text { Probability (Total } \\
\text { In Situ = 39) }\end{array}$ & $\begin{array}{c}\text { Valid } \\
\text { Probability } \\
(\%)\end{array}$ & Band & $\begin{array}{l}\text { Average } \\
\text { of Std }\end{array}$ & $\begin{array}{l}\text { Correlation } \\
\text { Coefficient }\end{array}$ & $\mathrm{SNR}^{3}$ & $\begin{array}{l}\text { Band Width } \\
\text { (nm) }\end{array}$ \\
\hline \multirow{10}{*}{ MODIS } & \multirow{10}{*}{$\begin{array}{c}61.54 \%(\text { matching } \\
\text { pairs }=24)\end{array}$} & \multirow{10}{*}{$4.9 \pm 1.7$} & 412 & 0.0071 & $-9.21 \%$ & 1208 & 15 \\
\hline & & & 443 & 0.0079 & $-12.39 \%$ & 1325 & 15 \\
\hline & & & $469(0.5 \mathrm{~km})$ & 0.0088 & $-20.64 \%$ & 316 & 20 \\
\hline & & & 488 & 0.0093 & $-30.31 \%$ & 1308 & 10 \\
\hline & & & 531 & 0.0114 & $-28.67 \%$ & 1385 & 10 \\
\hline & & & 547 & 0.0122 & $-20.01 \%$ & 1114 & 10 \\
\hline & & & $555(0.5 \mathrm{~km})$ & 0.0129 & $-25.88 \%$ & 302 & 20 \\
\hline & & & $645(0.25 \mathrm{~km})$ & 0.0040 & $-3.17 \%$ & 168 & 50 \\
\hline & & & 667 & 0.0031 & $42.10 \%$ & 1163 & 10 \\
\hline & & & 678 & 0.0028 & $37.94 \%$ & 1265 & 10 \\
\hline \multirow{5}{*}{ VIIRS } & \multirow{5}{*}{$\begin{array}{c}76.92 \%(\text { matching } \\
\text { pairs }=30)\end{array}$} & \multirow{5}{*}{$6.0 \pm 1.2$} & 410 & 0.0064 & $74.37 \%$ & 827 & 20 \\
\hline & & & 443 & 0.0090 & $72.67 \%$ & 774 & 18 \\
\hline & & & 486 & 0.0101 & $68.54 \%$ & 747 & 20 \\
\hline & & & 551 & 0.0126 & $78.58 \%$ & 586 & 20 \\
\hline & & & 671 & 0.0032 & $78.45 \%$ & 450 & 20 \\
\hline
\end{tabular}

${ }^{1}$ statistical daily average in whole Jan, 2014 for SO higher than $60 \mathrm{~S}$ ocean; ${ }^{2}$ standard deviation; ${ }^{3}$ signal noise ratio.

The average standard deviation between in situ and satellite derived Rrs is lower in MODIS (0.0076) than in VIIRS (0.0083). MODIS also has high spectral resolution band settings in visible wavelengths, with 10 bands. VIIRS only has six bands. However, the correlation coefficients are much higher from VIIRS (average of 74.522\%) than from MODIS (highest coefficients are 42.10\%), which can have significant contributions on chlorophyll-a estimation.

The current global OC3 algorithm for satellite chlorophyll-a estimation is built on the empirical relationship between chlorophyll-a concentration and blue-green band ratio. The sensitivity result (Figure 4) reveals that the appropriate blue band choice for SO is the 493-511 nm interval, which is higher than global case I waters, $\max (443,488) \mathrm{nm}$ band. The optimal band for green band in $\mathrm{SO}$ is between 564 and $617 \mathrm{~nm}$, which is also higher than global water green band $555 \mathrm{~nm}$. Therefore, no big advantage appears in either current satellite setting $486 / 555 \mathrm{~nm}$ band in VIIRS or $488 / 555 \mathrm{~nm}$ band in MODIS, both providing similar sensitivity for chlorophyll-a estimation.

We analyzed at sensor chlorophyll-a estimation from MODIS and VIIRS. Their chlorophyll-a products both show poor correlation with in situ chlorophyll-a (Figure 5e). Further comparisons between in situ and satellite blue or green bands display higher correlation from green band than blue band in both MODIS and VIIRS sensors (Figure 5b,d). However, VIIRS still performs better than MODIS in AP, in which both chlorophyll-a (Figure 5a,c) and Rrs (Figure 5b,d estimation are two times higher than MODIS. 


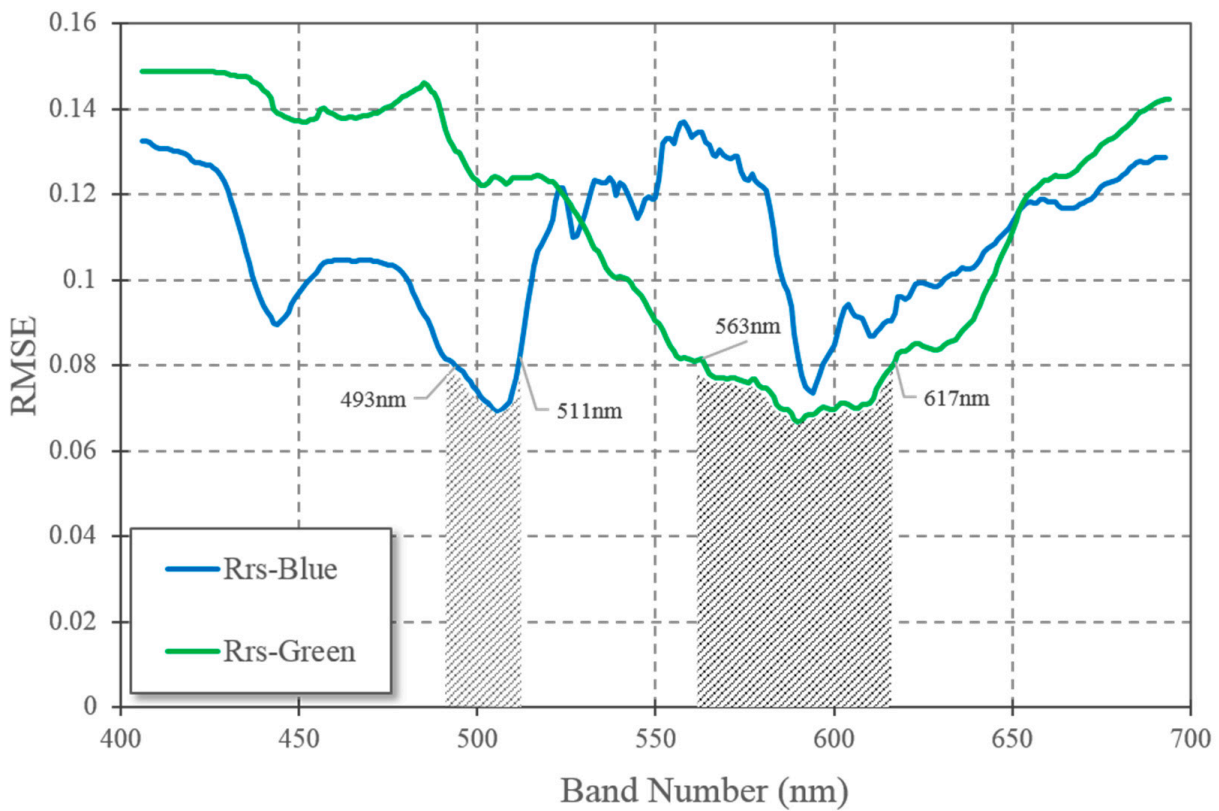

Figure 4. Blue-green band ratio model sensitivity on chlorophyll-a estimation, calculated from estimated residual error.

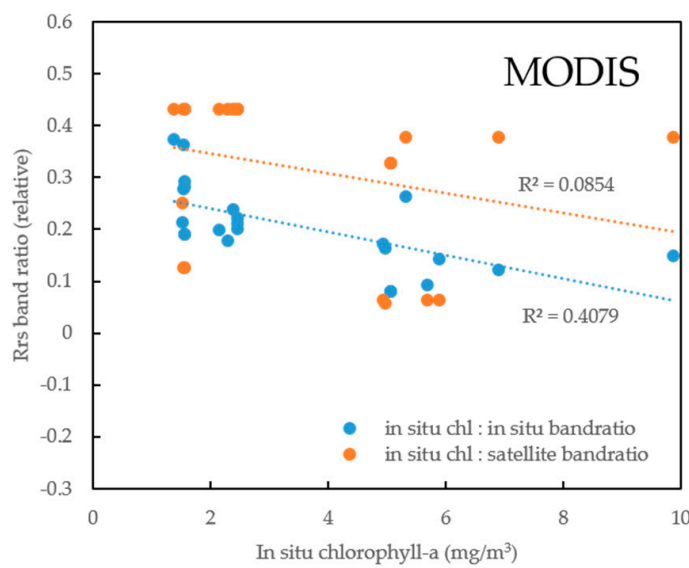

(a)

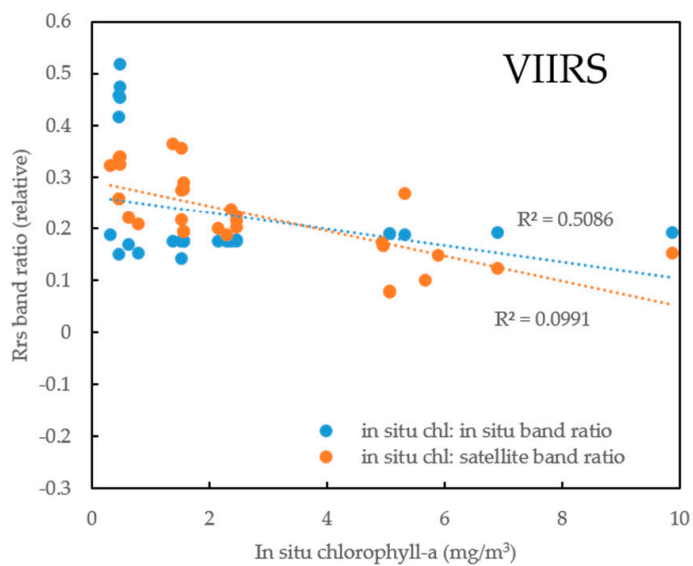

(c)

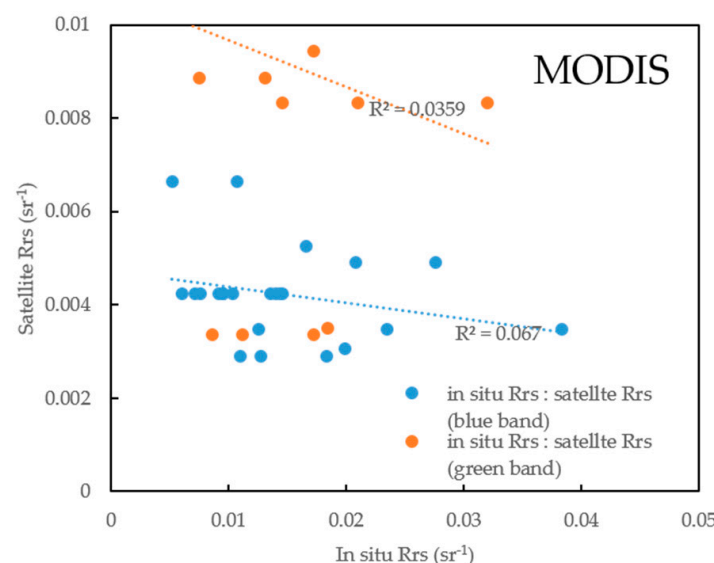

(b)

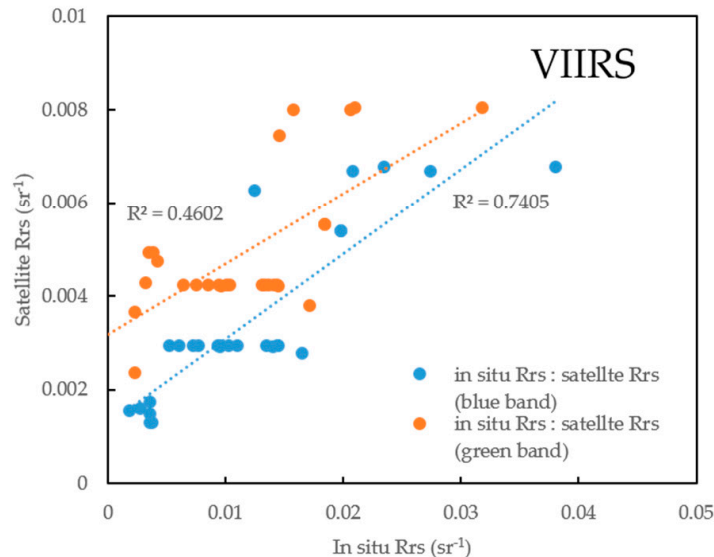

(d)

Figure 5. Cont. 


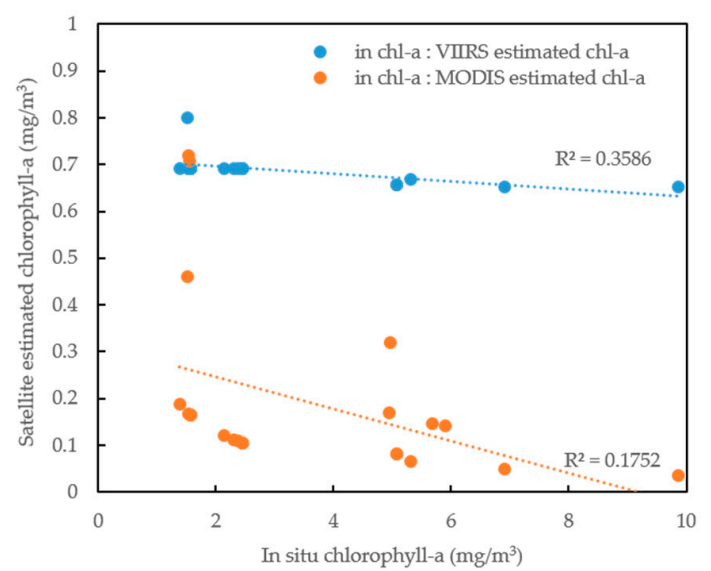

(e)

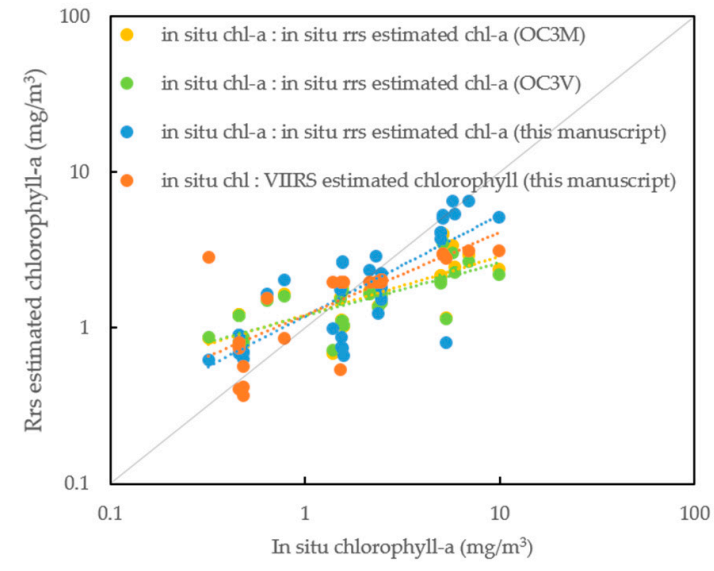

(f)

Figure 5. (a) Correlations between Rrs band ratio and in situ chlorophyll-a for MODIS matching pairs and its corresponding in situ Rrs; (b) Correlations between MODIS and in situ blue and green band Rrs; (c) Correlations between Rrs band ratio and in situ chlorophyll-a for VIIRS matching pairs and its corresponding in situ Rrs; (d) Correlations between VIIRS and in situ blue and green band Rrs; (e) Correlations between satellite estimated chlorophyll-a (VIIRS and MODIS, respectively) and in situ chlorophyll-a; (f) Correlations between various algorithms estimated chlorophyll-a and in situ chlorophyll-a. Algorithms include OC3M, OC3V, in situ Rrs band ratio algorithm (this manuscript), VIIRS Rrs band ratio algorithm (this manuscript).

The band set implies a potential improvement on chlorophyll-a estimation can be obtained if we had an ideal atmospheric correction. Current band ratio algorithms from field samples agree with chlorophyll-a within about $40 \%$ in MODIS and 50\% in VIIRS (Figure 5a,c).

It is worth noticing that through OC3M and OC3V coefficients and algorithm constraints, their chlorophyll-a estimation increases from a low correlation (8.54\% in MODIS and 9.91\% in VIIRS, from Figure $5 \mathrm{a}, \mathrm{c}$ ) to the correlation of $17 \%$ in MODIS and 35\% in VIIRS (Figure 5e).

Finally, we studied the coefficients for both OC3M and OC3V algorithms. Current algorithms appear to underestimate in $>2 \mathrm{mg} / \mathrm{m}^{3}$ chlorophyll-a and overestimation in $<2 \mathrm{mg} / \mathrm{m}^{3}$ chlorophyll-a samples (Figure 5f). No big difference exist between those two algorithms. Through all the comparisons, we improve the coefficients for VIIRS and increase its fitting coefficient to $53.12 \%$ (Table 2).

Table 2. Band ratio algorithms and their coefficients used in our study.

\begin{tabular}{|c|c|c|c|c|c|c|c|}
\hline \multicolumn{8}{|c|}{ Band Ratio Algorithm } \\
\hline \multicolumn{8}{|c|}{$\mathrm{chl}=10^{a 0+a 1 \times x+a 2 \times x^{2}+a 3 \times x^{3}+a 4 \times x^{4}}, \mathrm{x}=\frac{\max (\text { blue band })}{\text { green band }}$} \\
\hline & a0 & a1 & a2 & a3 & $\mathrm{a} 4$ & r2 & RMSE * \\
\hline OC $3 \mathrm{M}$ & 0.2424 & -2.7423 & 1.8017 & 0.0015 & -1.228 & $50.85 \%$ & 0.6304 \\
\hline OC3V & 0.2228 & -2.4683 & 1.5867 & -0.5275 & -0.7768 & $51.44 \%$ & 0.6688 \\
\hline $\begin{array}{l}\text { In situ Rrs band ratio } \\
\text { algorithm (this manuscript) }\end{array}$ & 0.3722 & -7.74 & -3.876 & 269.9 & -261.9 & $62.38 \%$ & 0.2762 \\
\hline $\begin{array}{l}\text { VIIRS Rrs band ratio } \\
\text { algorithm (this manuscript) }\end{array}$ & -4.177 & 31.85 & 4.1 & -297.1 & 383.6 & $53.12 \%$ & 0.2997 \\
\hline
\end{tabular}

* RMSE is $\frac{\sqrt[2]{\sum((\text { estimated chla })-(\text { field chla })) 2}}{N}$. 


\section{Discussion}

\subsection{Atmospheric Factors on Chlorophyll-a Retrieval}

Since the atmospheric reflection signals occupy $90 \%$ of total ocean color satellite signal [25], atmospheric calibration becomes a significant part in global water ocean color products estimation. Scientific researchers need an accuracy of $\sim 0.1 \%$ on sensor calibration, because $0.5 \%$ error in atmospheric correction will lead to a possible of $\sim 5 \%$ mistake in processing $\mathrm{nLw}$ [29]. According to Mao et al. [30], visible bands show more sensitivity than near infrared bands in aerosol scatter radiance. Therefore, near infrared bands were suggested to be used as the reference band for atmosphere calibration, like $750 \mathrm{~nm}$ in open ocean [23] or higher bands in coastal waters [31]. In this study, we applied in situ skylight radiance to remove atmosphere signals and took $946 \mathrm{~nm}$ as the reference band for atmospheric correction. Thus, these in situ Rrs spectrums could be thought as undergoing ideal atmospheric correction. Its difference with satellite Rrs uncovers the deficiency of current satellite processing procedure on $\mathrm{AP}$ water.

Our research finds that several minutes delay in measurement leads to big gaps in skylight across visible bands (Figure 2 Skylight $1 \& 2$ ), though in an identical location. Because aerosol and gas distribution in atmosphere occur across quite larger spatial and temporal scales, the spectrum shape gap between Skylight 1 and Skylight 2 (Figure 2) can be caused by cloud contamination. Records from Kider et al. [24] reported similar signs when using an ASD for measuring clouds. Currently, research seldom focuses on the clouds' impact on water-leaving reflectance, because most research usually removes cloud contaminated pixels directly. However, NASA pre-processing applies the NIR (near infrared) band ( $869 \mathrm{~nm}$ for MODIS, $862 \mathrm{~nm}$ for VIIRS) to avoid cloud contamination. Our result implies that clouds sometimes only have impacts on visible bands in AP (Skylight 2 in Figure 2), so the criteria flag on NIR band won't be contaminated. And, NIR band limitation works better on cirrus detection. Cumulus are also prevalent in AP because of its low pressure, and marine/biological cloudy weather [11,32], which is hardly detected in the NIR bands. Actually, Martin et al. [33] applied $555 \mathrm{~nm}$ for cloud detection due to highly spatial variation of cloud. Therefore, standard protocol on ocean color products keeps those cloud contaminated pixels in images and increases AP Rrs uncertainty in visible bands, especially in green band. Green band of $555 \mathrm{~nm}$ is located right in the middle of atmosphere contaminated bands (Skylight 2), which have lower correlation with in situ Rrs in both MODIS and VIIRS (Figure 5b,d).

Current atmospheric simulation in $\mathrm{SO}$ reveals atmosphere model deficiency on cloud, aerosol and ozone simulation [34], e.g., the $\mathrm{N}_{2} \mathrm{O}(604 \mathrm{~nm})$ and $\mathrm{O}_{2}(630 \mathrm{~nm})$ gas absorption windows (red arrows in Figure 2). Therefore, we need more information and datasets to understand special SO atmosphere's impact on its calibration from Rayleigh scatter, aerosol, ocean roughness and ocean bidirectional reflectance distribution [35,36]. Program SOCRATES pronounced great uncertainty and bias of cloud, aerosol and sea-air interaction simulation in $\mathrm{SO}$, and hosted a funding research to improve atmospheric correction algorithms in 2016-2019 [37].

\subsection{Bio-Optical Factors on Chlorophyll-a Retrieval}

Lower water leaving reflectance values and narrower blue-green band ratios in AP than case I water shows different water optical characteristics between AP and global ocean water (Figure 3). The narrow band ratio changing rate in AP will have overestimation in low chlorophyll-a water and have underestimation in high chlorophyll-a water using the OC3 model. That is also the case shown by Figure 5f. Other reports show same satellite chlorophyll-a estimation issues in SO [38,39]. Therefore, OC-like empirical algorithm should be recalibrated by SO in situ data as suggested by Gracia et al. [40].

Research found a broad variety of special phytoplankton community live in AP, such as diatoms and phaeocystis spp [9]. Those diatoms have larger cell sizes [41] than in other places and also have unique absorption and scattering features for light regulating. Larger phytoplankton will increase the package effect and decrease the light/absorption efficiency, thus modulating different Rrs pattern [42]. 
Other water constituents in water will also decrease Rrs correlation relationship with phytoplankton and chlorophyll-a concentration. Field samples show high CDOM concentration around $\mathrm{AP}$, which contributes $70 \%$ absorption of non-water absorption [43]. The main source of CDOM is from bacteria and krill in Weddell Sea and Bellingshausen Sea [44]. Those CDOM will interfere with the chlorophyll-a absorption peak [45], and cause uncertainty in chlorophyll-a estimation. In some cases, CDOM can be estimated by chlorophyll-a concentration [6,46]. Therefore, separating CDOM signal from Rrs (like bio-optical algorithm, GSM01 [47] and QAA [48]) is a better way to improve chlorophyll-a estimation in AP, where water is not only controlled by phytoplankton.

\subsection{Sensor Factors on Chlorophyll-a Retrieval}

Though with peculiar bio-optical properties, in situ Rrs from AP gets reliable chlorophyll-a estimations from an OC-like algorithm (Table 2 and Figure 5f). Those algorithms estimated chlorophyll-a range from 0.1 to $10 \mathrm{mg} / \mathrm{m}^{3}$, which have the same range with in situ chlorophyll-a. But there remains obvious underestimation in $>2.0 \mathrm{mg} / \mathrm{m}^{3}$ chlorophyll-a and overestimation in $<2.0 \mathrm{mg} / \mathrm{m}^{3}$ chlorophyll-a and their RMS surpasses $60 \%$ for both OC $3 \mathrm{M}$ and OC3V algorithms. The estimation errors implied great deficiencies in OC-like algorithms' coefficients. We improved the coefficients for OC3V and decreased its RMS to $29.97 \%$ and increased its chlorophyll-a estimation to a fitting coefficient of $53.12 \%$. Those coefficients modified VIIRS regional chlorophyll-a estimation accuracy, though this regional algorithm still needs more validation. Other research on modifying OC-like regional coefficients in SO are mainly based on MODIS [11], and no regional coefficients modifications are for VIIRS as far as we knew.

Large gaps exist in satellite estimated chlorophyll-a and in situ chlorophyll-a (Figure 5e). Satellite estimated chlorophyll-a showed big underestimation for in situ chlorophyll-a $\left(0.1-10 \mathrm{mg} / \mathrm{m}^{3}\right)$, between $0.01-1 \mathrm{mg} / \mathrm{m}^{3}$. Other than coefficients, OC-like algorithm has another uncertainty source, band ratios. Sensitivity test (Figure 4) declares little difference in band ratio selection for both MODIS and VIIRS. But our results presented a better validation from VIIRS blue and green band Rrs measurements than MODIS (Figure 5b,d). Those two sensors (MODIS AQUA and VIIRS) have quite similar overpass times in the afternoon from 2 to $5 \mathrm{pm}$ local time. Therefore, slight errors come from their measuring time gaps. The lower SNR, greater spectral range (Table 1) and higher spatial resolution $(750 \mathrm{~m})$ of VIIRS should be the reasons for its higher accuracy than MODIS (spatial resolution of $1 \mathrm{~km}$ in blue and green band) in AP. The broader coverage of VIIRS is also benefited from those sensor parameters. VIIRS gets its reprocessing improvement from its new SDR (Sensor data records) table and MSL12 (multi-sensor level-1 to level-2) data processing after 2014, which ocean color products are proved to be comparable to and even better than MODIS [49].

It is noted that VIIRS still needs more validation dataset for its products' evaluation after its launch in 2011. SeaBASS dataset shows that current validation dataset for VIIRS doesn't involve SO, especially $>60^{\circ}$ area [12]. Its better agreement with field samples are mostly concentrated on Hawaii, South Pacific Gyre, the U.S. East Coast, and the Gulf of Mexico coastal site [49]. Our data presented here proved its better application in AP chlorophyll-a estimation.

\section{Conclusions}

In this study, we collected hyper-spectral downwelling radiances and water-leaving Rrs around AP in January, 2014 and 2016. This hyper-spectral water bio-optical dataset helped to evaluate error sources from OC-like estimated chlorophyll-a in AP from three different aspects.

(1) Atmospheric correction. Though still lacking some absorption peaks in $\mathrm{N}_{2} \mathrm{O}(604 \mathrm{~nm})$ and $\mathrm{O}_{2}$ $(630 \mathrm{~nm})$ absorption peaks, Mid-Latitude Summer simulation model shows the best agreement with field skylight downwelling radiance from current atmosphere simulation models. Besides, the cloud in AP appears a severe issue for satellite sensor detection. Because low amount of cumulus doesn't cause absorption peaks in NIR band and only have impacts on visible green 
bands, satellite default cloud detection algorithm won't remove those pixels from current NIR threshold algorithms. Thus, green bands Rrs show poor agreement with in situ water leaving Rrs than blue bands from both MODIS and VIIRS.

(2) Water bio-optics. The peculiar water bio-optical features in AP creates narrower band-ratio variability than global case I water, which enhances its bias in chlorophyll-a estimation, causing underestimation in high chlorophyll-a water and overestimation in low chlorophyll-a water.

(3) Sensor comparisons. VIIRS shows better performance than MODIS in detecting Rrs with an average of $74.522 \%$ accuracy in field: satellite correlations. VIIRS also has higher spatial coverage than MODIS. After coefficient improvement, its chlorophyll-a estimation could reach a fitting coefficient of $53.12 \%$ and a RMS of $29.97 \%$.

Our hyper-spectral data from AP build a new way in understanding ocean color algorithms and provide an improved validation dataset for the newly launch VIIRS sensor. This study also shows a promising future for VIIRS ocean color products application in SO area.

Acknowledgments: This work was supported by the Chinese Polar Environment Comprehensive Investigation \& Assessment Programmes (CHINARE2015-02-04 \& CHINARE2016-02-04). SO in situ data is issued by Data-sharing Platform of Polar Science Data (http:/ / www.chinare.org.cn), which established by National Science \& Technology Infrastructures Polar Research Institute of China (PRIC) and Chinese National Arctic \& Antarctic Data Center (CN-NADC). Satellite Ocean Color data is provide by NASA Goddard Space Flight Center, Ocean Ecology Laboratory, Ocean Biology Processing Group. We would also like to appreciate the hard work and time of the anonymous reviewers.

Author Contributions: Chen Zeng and Huiping $\mathrm{Xu}$ conceived and designed the experiments; Chen Zeng performed the experiments, analyzed the data and wrote the paper. Huiping $\mathrm{Xu}$ and Andrew M. Fisher helped to improve and polish the paper.

Conflicts of Interest: The authors declare no conflict of interest.

\section{References}

1. Arrigo, K.R.; van Dijken, G.L.; Bushinsky, S. Primary production in the Southern Ocean, 1997-2006. J. Geophys. Res. 2008, 113, C08004. [CrossRef]

2. Eveleth, R.; Cassar, N.; Sherrell, R.M.; Ducklow, H.; Meredith, M.P.; Venables, H.J.; Lin, Y.; Li, Z. Ice melt influence on summertime net community production along the Western Antarctic Peninsula. Deep Sea Res. Part II 2016. [CrossRef]

3. Huang, K.; Ducklow, H.; Vernet, M.; Cassar, N.; Bender, M.L. Export production and its regulating factors in the West Antarctica Peninsula region of the Southern Ocean. Glob. Biogeochem. Cycles 2012, 26, 393-407. [CrossRef]

4. Moore, J.K.; Abbott, M.R. Phytoplankton chlorophyll distributions and primary production in the Southern Ocean. J. Geophys. Res. 2000, 105, 28709-28722. [CrossRef]

5. Trenberth, K.E.; Fasullo, J.T. Simulation of present day and 21st century energy budgets of the Southern Oceans. J. Clim. 2010, 23, 440-454. [CrossRef]

6. Reynolds, R.A.; Stramski, D.; Mitchell, B.G. A chlorophyll-dependent semi-analytical reflectance model derived from field measurements of absorption and backscattering coefficients within the Southern Ocean. J. Geophys. Res. 2001, 106, 7125-7138. [CrossRef]

7. Marrari, M.; Hu, C.; Daly, K. Validation of SeaWiFS chlorophyll a concentrations in the Southern Ocean: A revisit. Remote Sens. Environ. 2006, 105, 367-375. [CrossRef]

8. Dierssen, H.M.; Smith, R.C. Bio-optical properties and remote sensing ocean color algorithms for Antarctic Peninsula waters. J. Geophys. Res. 2000, 105, 26301-26312.

9. Gregg, W.W.; Casey, N.W. Global and regional evaluation of the SeaWiFS chlorophyll data set. Remote Sens. Environ. 2004, 93, 463-479. [CrossRef]

10. Kwok, R.; Comiso, J.C. Spatial Patterns of Variability in Antarctic Surface Temperature: Connections to the Southern Hemisphere Annular Mode and the Southern Oscillation. Geophys. Res. Lett. 2002, 29, 1705. [CrossRef] 
11. Gabric, A.J.; Shephard, J.M.; Knight, J.M.; Jones, G.; Trevena, A.J. Correlations between the satellite-derived seasonal cycles of phytoplankton biomass and aerosol optical depth in the Southern Ocean: Evidence for the influence of sea ice. Glob. Biogeochem. Cycles 2005, 19, GB4018. [CrossRef]

12. SeaBASS. Available online: http://seabass.gsfc.nasa.gov/ (accessed on 22 November 2016).

13. Mueller, J.L.; Morel, A.; Frouin, R.; Davis, C.; Arnone, R.; Carder, K.; Lee, Z.P.; Steward, R.G.; Hooker, S.; Mobley, C.D.; et al. Ocean Optics Protocols For Satellite Ocean Color Sensor Validation, Revision 4, Volume III: Radiometric Measurements and Data Analysis Protocols; Goddard Space Flight Space Center: Greenbelt, MD, USA, 2003; pp. 21-31.

14. Toole, D.A.; Siegel, D.A.; Menzies, D.W.; Neumann, M.J.; Smith, R.C. Remote-sensing reflectance determinations in the coastal ocean environment: Impact of instrumental characteristics and environmental variability. Appl. Opt. 2000, 39, 456-469. [CrossRef] [PubMed]

15. Morel, A.; Maritorena, S. Bio-optical properties of oceanic waters: A reappraisal. J. Geophys. Res. 2001, 106, 7163-7180. [CrossRef]

16. Amante, C.; Eakins, B.W. ETOPO1 1 Arc-Minute Global Relief Model: Procedures, Data Sources and Analysis; NOAA: Boulder, CO, USA, 2009.

17. Zhou, L.M.; Liu, Y.G.; Guo, P.F.; Tang, J.W.; Zhang, J. Study on the Fresnel reflectance of case 2 waters for diffuse sky-irradiance. In Ocean Monitor High Technology Strategy Symposium, Beijing, China, 2003; China Ocean Press: Beijing, China, 2014; pp. 260-265.

18. Tang, J.W.; Tian, G.L.; Wang, X.Y.; Wang, X.M.; Song, Q.J. The Methods of Water Spectra Measurement and Analysis I: Above-Water Method. J. Remote Sens. 2004, 8, 37-44.

19. Gitelson, A.A.; Schalles, J.F.; Hladik, C.M. Remote chlorophyll-a retrieval in turbid, productive estuaries: Chesapeake Bay case study. Remote Sens. Environ. 2007, 109, 464-472. [CrossRef]

20. Johnson, R.; Strutton, P.G.; Wright, S.W.; McMinn, A.; Meiners, K.M. Three improved satellite chlorophyll algorithms for the Southern Ocean. J. Geophys. Res. 2013, 118, 3694-3703. [CrossRef]

21. Hu, C.; Muller-Karger, F.E.; Taylor, C.J.; Carder, K.L.; Kelble, C.; Johns, E.; Heil, C.A. Red tide detection and tracing using MODIS fluorescence data: A regional example in SW Florida coastal waters. Remote Sens. Environ. 2005, 97, 311-321. [CrossRef]

22. Montes-Hugo, M.A.; Vernet, M.; Smith, R.; Carder, K. Phytoplankton size-structure on the western shelf of the Antarctic Peninsula: A remote-sensing approach. Int. J. Remote Sens. 2008, 29, 801-829. [CrossRef]

23. Gordon, H.R. Removal of atmospheric effects from the satellite imagery of the oceans. Appl. Opt. 1978, 17, 1631-1636. [CrossRef]

24. Kider, J.T., Jr.; Knowlton, D.; Newlin, J.; Li, Y.K.; Greenberg, D.P. A framework for the experimental comparison of solar and skydome illumination. ACM Trans. Graph. 2014, 33, 180.

25. Wang, M. Validation study of the SeaWiFS oxygen A-band absorption correction: Comparing the retrieved cloud optical thicknesses from SeaWiFS measurements. Appl. Opt. 1999, 38, 937-944. [CrossRef] [PubMed]

26. Rothman, L.S.; Gordon, I.E.; Barbe, A.; Benner, D.C.; Bernath, P.F.; Birk, M.; Boudon, V.; Brown, L.R.; Campargue, A.; Champion, J.P.; et al. The HITRAN 2008 molecular spectroscopic database. J. Quant. Spectrosc. Radiat. Transf. 2009, 110, 533-572. [CrossRef]

27. Ducklow, H.W.; Baker, K.; Martinson, D.G.; Quetin, L.B.; Ross, R.M.; Smith, R.C.; Stammerjohn, S.E.; Vernet, M.; Fraser, W. Marine pelagic ecosystems: The west Antarctic Peninsula. Philos. Trans. R. Soc. B 2007, 362, 67-94.

28. Esaias, W.E.; Abbott, M.R.; Barton, I.; Brown, O.B.; Campbell, J.W.; Carder, K.L.; Clark, D.K.; Evans, R.H.; Hoge, F.E.; Gordon, H.R.; et al. An overview of MODIS capabilities for ocean science observations. IEEE Trans. Geosci. Remote Sens. 1998, 36, 1250-1265.

29. Wang, M. Atmospheric Correction for Remotely-Sensed Ocean-Colour Products; Reports and Monographs of the International Ocean-Colour Coordinating Group (IOCCG): Dartmouth, MA, USA, 2010; p. 78.

30. Mao, Z.; Pan, D.; Hao, Z.; Chen, J.; Tao, B.; Zhu, Q. A potentially universal algorithm for estimating aerosol scattering reflectance from satellite remote sensing data. Remote Sens. Environ. 2014, 142, 131-140. [CrossRef]

31. Werdell, P.J.; Franz, B.A.; Bailey, S.W. Evaluation of shortwave infrared atmospheric correction for ocean color remote sensing of Chesapeake Bay. Remote Sens. Environ. 2010, 114, 2238-2247. [CrossRef]

32. McCoy, D.T.; Burrows, S.M.; Wood, R.; Grosvenor, D.P.; Elliott, S.M.; Ma, P.L.; Rasch, P.J.; Hartmann, D.L. Natural aerosols explain seasonal and spatial patterns of Southern Ocean cloud albedo. Sci. Adv. 2015, 1, e1500157. [CrossRef] [PubMed] 
33. Martins, J.V.; Tanré, D.; Remer, L.; Kaufman, Y.; Mattoo, S.; Levy, R. MODIS Cloud screening for remote sensing of aerosols over oceans using spatial variability. Geophys. Res. Lett. 2002, 29. [CrossRef]

34. Liou, K.N. An Introduction to Atmospheric Radiation; Academic Press: San Diego, CA, USA, 2012.

35. Wang, M. Effects of ocean surface reflectance variation with solar elevation on normalized water-leaving radiance. Appl. Opt. 2006, 45, 4122-4128. [CrossRef] [PubMed]

36. Wang, M. Aerosol polarization effects on atmospheric correction and aerosol retrievals in ocean color remote sensing. Appl. Opt. 2006, 45, 8951-8963. [CrossRef] [PubMed]

37. McFarquhar, G.M.; Wood, R.; Bretherton, C.S.; Alexander, S.; Jakob, C.; Marchand, R.; Protat, A.; Quinn, P.; Siems, S.T.; Weller, R.A. The Southern Ocean Clouds, Radiation, Aerosol Transport Experimental Study (SOCRATES): An Observational Campaign for Determining Role of Clouds, Aerosolsand Radiation in Climate System. In Proceedings of the AGU Fall Meeting, San Francisco, CA, USA, 15-19 December 2014.

38. Clementson, L.A.; Parslow, J.S.; Turnbull, A.R.; McKenzie, D.C.; Rathbone, C.E. Optical properties of waters in the Australasian sector of the Southern Ocean. J. Geophys. Res. Oceans 2001, 106, 31611-31625. [CrossRef]

39. Bélanger, S.; Ehn, J.K.; Babin, M. Impact of sea ice on the retrieval of water-leaving reflectance, chlorophyll a concentration and inherent optical properties from satellite ocean color data. Remote. Sens. Environ. 2007, 111, 51-68. [CrossRef]

40. Garcia, C.A.E.; Garcia, V.M.T.; McClain, C.R. Evaluation of SeaWiFS chlorophyll algorithms in the Southwestern Atlantic and Southern Oceans. Remote Sens. Environ. 2005, 95, 125-137. [CrossRef]

41. Brody, E.; Mitchell, B.G.; Holm-Hansen, O.; Vernet, M. Species-dependent variations of the absorption coefficient in the Gerlache Strait. Antarct. J. 1992, 27, 160-162.

42. Tripathy, S.C.; Pavithran, S.; Sabu, P.; Naik, R.K.; Noronha, S.B.; Bhaskar, P.V.; Anilkumar, N. Is phytoplankton productivity in the Indian Ocean sector of Southern Ocean affected by pigment packaging effect? Curr. Sci. 2014, 107, 1019-1026.

43. Siegel, D.A.; Maritorena, S.; Nelson, N.B.; Hansell, D.A.; Lorenzi-Kayser, M. Global distribution and dynamics of colored dissolved and detrital organic materials. J. Geophys. Res. Oceans 2002, 107, C12. [CrossRef]

44. Ortega-Retuerta, E.; Frazer, T.K.; Duarte, C.M.; Ruiz-Halpern, S.; Tovar-Sánchez, A.; Arrieta López de Uralde, J.M.; Reche, I. Biogeneration of chromophoric dissolved organic matter by bacteria and krill in the Southern Ocean. Limnol. Oceanogr. 2009, 54, 1941-1950.

45. Siegel, D.A.; Maritorena, S.; Nelson, N.B.; Behrenfeld, M.J. Independence and interdependencies among global ocean color properties: Reassessing the bio-optical assumption. J. Geophys. Res. 2005, 110, 691-706. [CrossRef]

46. Ciotti, A.M.; Bricaud, A. Retrievals of a size parameter for phytoplankton and spectral light absorption by colored detrital matter from water-leaving radiances at SeaWiFS channels in a continental shelf region off Brazil. Limnol. Oceanogr. Methods 2006, 4, 237-253.

47. Maritorena, S.; Siegel, D.A.; Peterson, A. Optimization of a Semi-Analytical Ocean Color Model for Global Scale Applications. Appl. Opt. 2002, 41, 2705-2714. [CrossRef] [PubMed]

48. Lee, Z.; Carder, K.L.; Arnone, R.A. Deriving inherent optical properties from water color: A multiband quasi-analytical algorithm for optically deep waters. Appl. Opt. 2002, 41, 5755-5772. [CrossRef] [PubMed]

49. Wang, M.; Liu, X.; Tan, L.; Jiang, L.; Son, S.; Shi, W.; Rausch, K.; Voss, K. Impacts of VIIRS SDR performance on ocean color products. J. Geophys. Res. Atmos. 2013, 118, 10347-10360. [CrossRef]

(C) 2016 by the authors; licensee MDPI, Basel, Switzerland. This article is an open access article distributed under the terms and conditions of the Creative Commons Attribution (CC-BY) license (http://creativecommons.org/licenses/by/4.0/). 